\title{
High Expression of p62 Protein Is Associated with Poor Prognosis and Aggressive Phenotypes in Endometrial Cancer
}

\author{
Reiko Iwadate, ${ }^{* \dagger}$ Jun Inoue, ${ }^{* \dagger}$ Hitoshi Tsuda, ${ }^{\S}$ Masashi Takano, ${ }^{\llbracket}$ Kenichi Furuya, ${ }^{\llbracket}$ Akira Hirasawa, ${ }^{\dagger}$ Daisuke Aoki, ${ }^{\dagger}$ and \\ Johji Inazawa* ${ }^{* 1}$
}

\begin{abstract}
From the Department of Molecular Cytogenetics, * Medical Research Institute and Graduate School of Medical and Dental Science, the Bioresource Research Center ${ }^{\ddagger}$ and the Department of Genome Medicine, ${ }^{\|}$Hard Tissue Genome Research Center, Tokyo Medical and Dental University, Tokyo; the Department of Obstetrics and Gynecology, ${ }^{\dagger}$ School of Medicine, Keio University, Tokyo; and the Departments of Pathology $y^{\S}$ and Obstetrics and Gynecology, ${ }^{\Uparrow}$ National Defense Medical College, Saitama, Japan
\end{abstract}

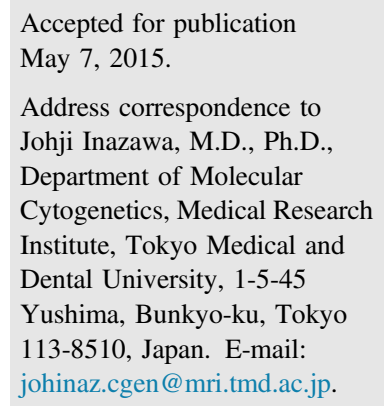

\begin{abstract}
High expression of SQSTM1/p62 (p62) protein, which functions as a hub of oncogenic signaling pathways, has been detected in several human cancers. However, the clinicopathological and functional contribution of p62 expression is largely unknown in endometrial cancers (ECs). In this study, we assessed the expression status of p62 in primary ECs $(n=194)$ by immunohistochemistry and analyzed its clinical significance. Although p62 was expressed in the cytoplasm and/or nucleus in primary ECs, we observed that an expression subtype, high expression of cytoplasmic p62 but low expression of nuclear p62 (cytoplasm ${ }^{\text {High }} /$ nucleus $^{\text {Low }}$ ), significantly correlated with nonendometrioid types $(P=0.002)$, high grade $(P<0.001)$, deep myometrial invasion $(P=0.025)$, vascular invasion $(P=0.012)$, and poor prognosis $(P<0.001)$, and may be an independent prognostic marker of ECs $(P=0.011)$. Furthermore, RNA interference-mediated inhibition of p62 expression in the HEC-1A EC cell line led to the reduction of invasiveness and resistance to oxidative stress in vitro, as well as the suppression of in vivo tumor growth in an orthotopic mouse model of ECs. High expression of cytoplasmic p62 is a novel prognostic biomarker of ECs, and excess p62 expression may functionally contribute to the acquirement of malignant phenotypes in EC cells. (Am J Pathol 2015, 185: 2523-2533; http:// dx.doi.org/10.1016/j.ajpath.2015.05.008)
\end{abstract}

Endometrial cancer (EC) is the most common gynecologic malignancy in developed countries, ${ }^{1}$ and its incidence is increasing in several countries. ${ }^{2-4}$ Although almost all ECs are diagnosed at an early stage, approximately $15 \%$ are found in advanced stages, with tumor invasion and metastasis into the uterine serosa, adnexa, vagina, and/or lymph nodes, and are associated with a decrease in survival rate. ${ }^{2}$ To combat this potentially lethal EC, new prognostic markers based on biological evidence at the molecular level are needed.

SQSTM1/p62 (hereafter referred to as p62) serves physiologically as a hub for various signal pathways for cell survival and cell death. ${ }^{5}$ This protein is known to be one of the selective substrates of the autophagy, a cellular degradation system, by which cytoplasmic components, organelles, and incorporated p62 protein are degraded. ${ }^{5-8}$ Although mice lacking Atg5 or Atg7, which are essential components of the autophagy pathway, show elevated rates of spontaneous tumor formation accompanied by p62 accumulation, these tumor sizes are reduced by deletion of $p 62$, suggesting that $\mathrm{p} 62$ accumulation may contribute to tumor progression. ${ }^{5,9,10}$ Furthermore, it has

\footnotetext{
Supported in part by Japan Society for the Promotion of Science Grants-inAid for Scientific Research (A) 25250019 (J.Ina.) and (C) 24590372 (J.Ino.); Grants-in-Aid for Scientific Research on Innovative Areas Integrative Systems Understanding of Cancer for Advanced Diagnosis, Therapy and Prevention 22134002 (J.Ina.), Project for Development of Innovative Research on Cancer Therapeutics (P-Direct), Scientific Research on Priority Areas and Innovative Areas (J.Ina.), and the Global Center of Excellence Program from the Ministry of Education, Culture, Sports, Science, and Technology (J.Ina.), Japan; Foundation for Promotion of Cancer Research for the 3rd Term Comprehensive 10-Year-Strategy (H24-the 3rd Term-Young-002) (J.Ino.) from the Ministry of Health, Labour and Welfare, Japan; and the Foundation for Promotion of Cancer Research, Tokyo, Japan.

Disclosures: None declared.
} 
been demonstrated that excess p62 expression may be involved in the activation of oncogenic signaling, including the NF- $\mathrm{KB},{ }^{5}$ Wnt/ $\beta$-catenin, ${ }^{11}$ mammalian target of rapamycin, ${ }^{12,13}$ and nuclear factor (erythroid-derived 2)-like 2 (NRF2) $)^{5,10,14}$ pathways. Furthermore, abnormal expression of p62 has been detected in several cancers, including prostate, ${ }^{15,16}$ kidney, ${ }^{13}$ liver, ${ }^{10}$ lung, ${ }^{17}$ breast, ${ }^{18-20}$ oral, ${ }^{21,22}$ and ovarian ${ }^{23}$ cancer cases. Thus, growing lines of evidence have indicated that p62 may function as an oncogene in human cancers.

However, it remains to be clarified whether p62 protein is highly expressed in ECs, and how p62 protein contributes to the malignancy of tumor cells and the prognosis of patients. Herein, we examined the expression of p62 in patients with $\mathrm{EC}$ and analyzed the clinicopathological implication of p62 expression status. Although p62 was expressed in the cytoplasm (Cyto) and/or nucleus (Nuc) in primary ECs, we found that an expression subtype of a high level of cytoplasmic p62 and a low level of nuclear p62 (Cyto $\left.{ }^{\text {High }} / \mathrm{Nuc}^{\mathrm{Low}}\right)$ was associated with aggressive phenotype and poor clinical outcome, irrespective of histological type. Furthermore, using an EC cell line, we demonstrated that the inhibition of p62 leads to a reduction in invasive activity, resistance to oxidative stress, and tumor growth in vivo. Thus, the findings in this study indicate that p62 may be used as a biomarker for the prognostic prediction of patients with $\mathrm{EC}$, and that $\mathrm{p} 62$ expression is involved in the aggressive phenotype of EC cells.

\section{Materials and Methods}

\section{Patients and Tumor Specimens}

Formalin-fixed, paraffin-embedded tissue blocks of primary ECs from 194 consecutive patients were used to construct tissue microarrays (TMAs). All patients underwent surgery at the National Defense Medical College Hospital (Saitama, Japan) from 1990 to 2007 and were followed up for 5 years. Of the 194 patients, $175(90.2 \%)$ were diagnosed with endometrioid adenocarcinoma, and $24(12.4 \%)$ died of cancer during the study period, with a median interval of 22.0 months (range, 2.0 to 58.0 months) from surgery to death. The median follow-up period of the 117 survivors (60.3\%) was 98.0 months (range, 61.0 to 235.0 months). Tumor histological types and grades were classified according to the World Health Organization criteria. Clinical stages of the disease were classified according to the International Federation of Gynecology and Obstetrics system of 1988. The clinicopathological characteristics are described in Table 1. All patients gave their written informed consent before study. This study was approved by the ethics committee of the National Defense Medical College, Keio University (Tokyo, Japan), and Tokyo Medical and Dental University (Tokyo, Japan).

\section{Cell Cultures}

A total of 13 human EC cell lines were used in this study. HEC-1, HEC-50B, HEC-59, HEC-151, HEC-251, and
HEC-265 cells were obtained from the Japanese Collection of Research Bioresource cell bank (Osaka, Japan). HEC-1A, HEC-1B, and HEC-108 cells were kindly provided by Dr. Hiroyuki Kuramoto (Kanagawa Health Service Association, Kanagawa, Japan). ${ }^{24,25}$ HHUA and HOOUA cells were kindly provided by Dr. Isamu Ishiwata (Ishiwata Obstetrics and Gynecology Hospital, Ibaraki-ken, Japan). ${ }^{26,27}$ Ishikawa cells were kindly provided by Dr. Masato Nishida (Kasumigaura Medical Center, Tsuchiura, Japan). ${ }^{28}$ SNG-M cells were established in our laboratory. ${ }^{29}$ HEC-1A cells were grown in McCoy's 5A medium containing 10\% fetal bovine serum (FBS). HHUA and SNG-M cells were grown in Ham's F12 medium containing $15 \%$ or $20 \%$ FBS, respectively. HOOUA and Ishikawa cells were grown in Dulbecco's modified Eagle's medium containing 10\% FBS. The other eight cell lines were grown in Eagle's minimal essential medium containing $10 \%$ FBS. All cell lines were maintained at $37^{\circ} \mathrm{C}$ with $5 \% \mathrm{CO}_{2}$.

\section{Reagents and Antibodies}

Hydrogen peroxide and leptomycin B were purchased from Wako Pure Chemical (Osaka, Japan) and Cell Signaling Technology (Boston, MA), respectively. Mouse anti-p62 antibody (Santa Cruz Biotechnology, Dallas, TX) was used for Western blot analysis, immunofluorescence analysis, and immunohistochemistry. Rabbit anti-p62 antibody (Medical \& Biological Laboratories, Nagoya, Japan) was used for immunohistochemistry of tumor tissues from mice. Mouse anti- $\beta$ actin antibody (Sigma-Aldrich, St. Louis, MO) was used for Western blot analysis.

\section{Immunohistochemical Analysis}

We constructed TMAs from tissue blocks prepared from 194 EC tumors using a Tissue Microarrayer (Beecher Instruments, Silver Spring, MD), as previously described. ${ }^{30}$ Immunohistochemistry was performed on TMA sections, cell pellet sections from cell lines, and tumor sections from mice. The sections were deparaffinized in xylene, and rehydrated using graded ethanol $(100 \%, 90 \%, 80 \%, 70 \%$, and $50 \%$ ) to water. After the retrieval of antigens by boiling in 10 $\mathrm{mmol} / \mathrm{L}$ citrate buffer ( $\mathrm{pH} 6.0$ ), the sections were treated with $0.3 \%$ hydrogen peroxide in methanol to inactivate endogenous peroxidase. Non-specific binding was blocked by incubation in horse serum (for TMA sections and cell pellet sections from cell lines) or goat serum (for tumor sections from mice) in phosphate-buffered saline (PBS). Next, the slides were incubated with mouse (for TMA sections or cell pellet sections from cell lines) or rabbit (for tumor sections from mice) anti-p62 antibodies (dilution for both, 1:2000) overnight at room temperature. The bound antibody was visualized using diaminobenzidine as a chromogen (VECTASTAIN Elite ABC kit; Vector Laboratories, Burlingame, $\mathrm{CA})$, and the sections were lightly counterstained with hematoxylin. 
Immunohistochemical evaluation was performed by three people (R.I., J. Inoue, and H.T.), and cases with discrepant grades were re-evaluated by discussion until consensus was achieved. The intensity score of cytoplasmic p62 expression was determined as 0 (no expression), 1+ (weak), or $2+$ (strong). Specimens with $10 \%$ or more of immunoreactive tumor cells with intensity scores of $2+$ were considered high expression. Specimens with $<10 \%$ of immunoreactive tumor cells with intensity scores of $2+$, or those with almost all tumor cells with intensity scores of $1+$ or 0 , were considered low expression. For evaluation of nuclear expression status, specimens were classified as high or low expression if $>5 \%$ or $<5 \%$ of tumor cells had nuclear p62 staining, respectively. On the basis of the distribution (Cyto or Nuc) and the expression level (high or low), specimens were classified into four subtypes: type A (Cyto ${ }^{\text {Low/ }}$ $\left.\mathrm{Nuc}^{\text {Low }}\right)$, type B $\left(\mathrm{Cyto}^{\text {Low }} / \mathrm{Nuc}^{\mathrm{High}}\right)$, type C $\left(\mathrm{Cyto}^{\mathrm{High}} /\right.$ $\left.\mathrm{Nuc}^{\mathrm{High}}\right)$, and type D $\left(\mathrm{Cyto}^{\mathrm{High}} / \mathrm{Nuc}^{\mathrm{Low}}\right)$.

\section{Generation of Stably p62-Inhibited HEC-1A Cells and Stably p62-0verexpressed HEC-251 Cells}

shRNA oligonucleotides were annealed and inserted into the pGreenPuro vector (System Biosciences, Mountain View, CA). The full length of p62 cDNA was inserted into the pCDHCMV-MCS-EF1-RFP+Puro vector (System Biosciences). Lentivirus was next prepared using the pPACK Packaging Kit (System Biosciences), according to the manufacturer's instructions. The virus titer was measured in infectious units per $\mathrm{mL}$ by an RT-PCR-based method using the Global UltraRapid Lentiviral Titer Kit (System Biosciences). Cells were infected with 5 multiplicity of infection of lentivirus with either empty vector (as a control) or p62-shRNA vector using TransDux (System Biosciences). The infected cells were then selected by treatment with $1 \mu \mathrm{g} / \mathrm{mL}$ of puromycin (Sigma-Aldrich). Sequences of the oligonucleotides were as follows: sense, 5'-TCGAGGAAATGGGTCCACCAGGAATTCAAGAGATTCCTGGTGGACCCATTTCTTTTTTA- ${ }^{\prime}$; and antisense, 5'-AGCTTAAAAAAGAAATGGGTCCACCAGGAATCTCTTGAATTCCTGGTGGACCCATTTCC-3'.

\section{Transfection of siRNAs}

The siRNAs for p62/SQSTM1 (siGENOME SMARTpool; M-010230-00-0005) and nontargeting negative control (siGENOME SMARTpool; D-001206-14-05) were obtained from GE Dharmacon (Pittsburgh, PA). The cells were transfected with $10 \mathrm{nmol} / \mathrm{L}$ of each siRNA using Lipofectamine RNAiMAX (Invitrogen, Carlsbad, CA), according to the manufacturer's instructions.

\section{Immunofluorescence Analysis}

Cells were fixed in $10 \%$ trichloroacetic acid and permeabilized with $0.5 \%$ Triton X-100 (Sigma-Aldrich) in PBS. After blocking with PBS containing $1 \%$ bovine serum albumin and
$0.01 \%$ Triton $\mathrm{X}-100$ for 1 hour at $4^{\circ} \mathrm{C}$, the cells were incubated with mouse anti-p62 (dilution, 1:2000) overnight at $4^{\circ} \mathrm{C}$. Bound antibody was visualized using Alexa Fluor 488 anti-mouse IgG antibody (dilution, 1:2000; Invitrogen). The cells were mounted by VECTASHIELD Mounting Medium with DAPI (Vector Laboratories) and observed under a fluorescence microscope (model DM6000 B; Leica, Wetzlar, Germany).

\section{Western Blot Analysis}

Whole-cell lysate was prepared in a 2\% SDS sample buffer $(\mathrm{pH}$ 6.8 ) and sonicated. The proteins in the lysate were resolved by SDS-PAGE and transferred to a polyvinylidene difluoride membrane. After blocking with tris-buffered saline containing $5 \%$ nonfat dry milk and $0.05 \%$ Tween-20 for 1 hour at room temperature, the membrane was reacted overnight at $4^{\circ} \mathrm{C}$ with mouse anti-p62 (dilution, 1:2000) or mouse anti- $\beta$-actin (dilution, 1:5000) antibody. The membrane was washed and exposed to horseradish peroxidase-conjugated goat anti-mouse IgG antibody (dilution, 1:5000) for 2 hours at room temperature. The bound antibodies were visualized with a western detection kit, according to the manufacturer's instructions (SuperSignal West Dura; Thermo Fisher Scientific, Waltham, MA).

\section{Transwell Migration and Invasion Assays}

The 24-well modified chambers (BD BioCoat; BD Biosciences, Franklin Lakes, NJ) were used as described elsewhere. ${ }^{31}$ Cells were transfected with siRNAs in a 6-well plate $\left(1 \times 10^{6}\right.$ cells per well) for 24 hours. Transiently or stably p62-inhibited cells were transferred into the upper chambers in serum-free medium $\left(1 \times 10^{5}\right.$ cells per well). After incubation for 24 hours, cells that migrated or invaded into the lower chambers, which contained $10 \%$ FBS as the chemoattractant, were stained with $0.1 \%$ crystal violet in $4 \%$ formaldehyde in PBS. The stained cells were counted using ImageJ software version $1.47(\mathrm{NIH}$, Bethesda, MD; http://imagej.nih.gov/ij).

\section{Assay for Cell Survival and Growth}

Cell survival and growth were assessed by a crystal violet staining assay. The cells were washed in PBS and stained with $0.1 \%$ crystal violet in $4 \%$ formaldehyde in PBS. Excess crystal violet solution was discarded and, after being completely air dried, the stained cells were lysed with a 2\% SDS solution by shaking the plates for 1 hour. OD was measured at $560 \mathrm{~nm}$ using a microplate reader (ARVOmx; Perkin Elmer, Waltham, $\mathrm{MA}$ ), and the OD ratio of every well was determined. For the cell survival assay, the OD value of cells in the control wells was arbitrarily set at $100 \%$ to determine the percentage of viable cells. For the cell growth assay, the OD values of the cells on day 0 were arbitrarily set at 1.0 to determine the growth rate.

\section{In Vivo Tumor Growth Assay}

We used a modified orthotopic model of ECs by injection of cells into the uterus of mice. ${ }^{32}$ Seven-week-old female BALB/c 
Table 1 Correlation between p62 Expression and Clinicopathological Variables in Patients with Endometrial Cancers

\begin{tabular}{|c|c|c|c|c|c|c|c|}
\hline \multirow[b]{2}{*}{ Variables } & \multirow[b]{2}{*}{ Total No. } & \multicolumn{3}{|c|}{ Expression level of cytoplasmic p62 } & \multicolumn{3}{|c|}{ Subtypes of p62 expression status* } \\
\hline & & Low & High & $P^{\dagger}$ & Types A, B, and C & Type D & $P^{\dagger}$ \\
\hline No. $(\%)$ & 194 & $156(80.4)$ & $38(19.6)$ & & $165(85.1)$ & $29(14.9)$ & \\
\hline \multicolumn{8}{|l|}{ Age, years ${ }^{\ddagger}$} \\
\hline$\leq 60$ & 120 & $104(86.7)$ & $16(13.3)$ & 0.005 & $108(90.0)$ & $12(10.0)$ & 0.014 \\
\hline$>60$ & 74 & $52(70.3)$ & $22(29.7)$ & & $57(77.0)$ & $17(23.0)$ & \\
\hline \multicolumn{8}{|c|}{ Histological type (endometrioid vs others) } \\
\hline Endometrioid & 175 & $145(82.9)$ & $30(17.1)$ & 0.015 & $154(88.0)$ & $21(12.0)$ & 0.002 \\
\hline Serous & 9 & $4(44.4)$ & $5(55.6)$ & & $4(44.4)$ & $5(55.6)$ & \\
\hline Mucinous & 4 & $4(100.0)$ & $0(0.0)$ & & $4(100.0)$ & $0(0.0)$ & \\
\hline Clear cell & 3 & $2(66.7)$ & $1(33.3)$ & & $2(66.7)$ & $1(33.3)$ & \\
\hline Adenosquamous & 2 & $1(50.0)$ & $1(50.0)$ & & $1(50.0)$ & $1(50.0)$ & \\
\hline Undifferentiated & 1 & $0(0.0)$ & $1(100.0)$ & & $0(0.0)$ & $1(100.0)$ & \\
\hline \multicolumn{8}{|c|}{ Tumor grade (1-2 vs 3 ) } \\
\hline 1 & 101 & $90(89.1)$ & $11(10.9)$ & $<0.001$ & $91(90.1)$ & $10(9.9)$ & $<0.001$ \\
\hline 2 & 58 & $47(81.0)$ & $11(19.0)$ & & $53(91.4)$ & $5(8.6)$ & \\
\hline 3 & 35 & $19(54.3)$ & $16(45.7)$ & & $21(60.0)$ & $14(40.0)$ & \\
\hline \multicolumn{8}{|c|}{ Myometrial invasion, $\%$} \\
\hline$\leq 50$ & 104 & $90(86.5)$ & $14(13.5)$ & 0.021 & $94(90.4)$ & $10(9.6)$ & 0.025 \\
\hline$>50$ & 90 & $66(73.3)$ & $24(26.7)$ & & $71(78.9)$ & $19(21.1)$ & \\
\hline \multicolumn{8}{|l|}{ Vascular invasion } \\
\hline Negative & 95 & $86(90.5)$ & $9(9.5)$ & $<0.001$ & $87(91.6)$ & $8(8.4)$ & 0.012 \\
\hline Positive & 99 & $70(70.7)$ & $29(29.3)$ & & $78(78.8)$ & $21(21.2)$ & \\
\hline \multicolumn{8}{|c|}{ Lymph node metastasis } \\
\hline Negative & 164 & $136(82.9)$ & $28(17.1)$ & 0.039 & $143(87.2)$ & $21(12.8)$ & 0.089 \\
\hline Positive & 30 & $20(66.7)$ & $10(33.3)$ & & $22(73.3)$ & $8(26.7)$ & \\
\hline \multicolumn{8}{|c|}{ FIGO stage (I-II vs III-IV) } \\
\hline I & 143 & $117(81.8)$ & $26(18.2)$ & 0.129 & $124(86.7)$ & $19(13.3)$ & 0.111 \\
\hline II & 12 & $11(91.7)$ & $1(8.3)$ & & $11(91.7)$ & $1(8.3)$ & \\
\hline III & 32 & $26(81.3)$ & $6(18.8)$ & & $27(84.4)$ & $5(15.6)$ & \\
\hline IV & 7 & $2(28.6)$ & $5(71.4)$ & & $3(42.9)$ & $4(57.1)$ & \\
\hline \multicolumn{8}{|l|}{ Residual tumor } \\
\hline Negative & 171 & $141(82.5)$ & $30(17.5)$ & 0.088 & $149(87.1)$ & $22(12.9)$ & 0.054 \\
\hline Positive & 23 & $15(65.2)$ & $8(34.8)$ & & $16(69.6)$ & $7(30.4)$ & \\
\hline
\end{tabular}

Data are given as number (percentage) unless otherwise indicated.

*Expression status of p62 was determined by immunohistochemistry and was classified into four types (A-D), as described in Materials and Methods.

${ }^{\dagger}$ Using $\chi^{2}$ or Fisher exact test, as appropriate. Statistically significant values are boldfaced.

${ }^{\ddagger}$ Median age was 59 years (range, 34 to 85 years).

FIG0, International Federation of Gynecology and Obstetrics.

nude mice were purchased from the Charles River Laboratories (Kanagawa, Japan). A laparotomy with a transverse incision was performed under anesthesia, followed by ligation at the boundary division of the uterine fundus and cervix using 4-0 Vicril (Ethicon, New Brunswick, NJ). Tumor cells $\left(5 \times 10^{6}\right.$ cells $)$ suspended in $30 \mu \mathrm{L}$ of Matrigel (BD Biosciences, San Jose, $\mathrm{CA}$ ) were injected into the right uterine cavity via a 30 -gauge needle. After gelation of the Matrigel (waiting time, 90 to 120 seconds), the needle was gently removed. The incision was closed after inspection to check for no leakage. The development of uterine tumors and para-aortic lymph node metastases was evaluated with sacrifice of the mice at 8 or 12 weeks after injection.

\section{Statistical Analysis}

Correlation between p62 expression in primary ECs and clinicopathological variables was analyzed by the $\chi^{2}$ or
Fisher exact test. Survival data were analyzed by the Kaplan-Meier method, and compared with the expression pattern of p62 by log-rank test. For in vitro assays, differences in population mean between the control and test groups were compared by $t$-test. For the in vivo tumor growth assay, differences in tumor size derived from control cells and p62-inhibited cells were compared by $U$ test. $P<0.05$ was considered statistically significant.

\section{Results}

Clinicopathological and Prognostic Implications of p62 Expression

We first optimized conditions for immunostaining of p62 by using EC cell lines. Among the 13 EC cell lines examined, the expression level of p62 protein was highest in HEC-1A 
A

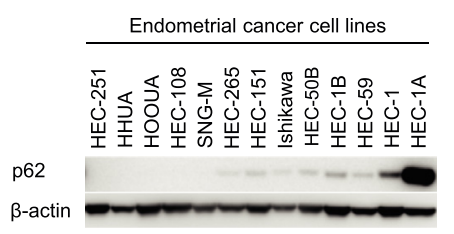

B
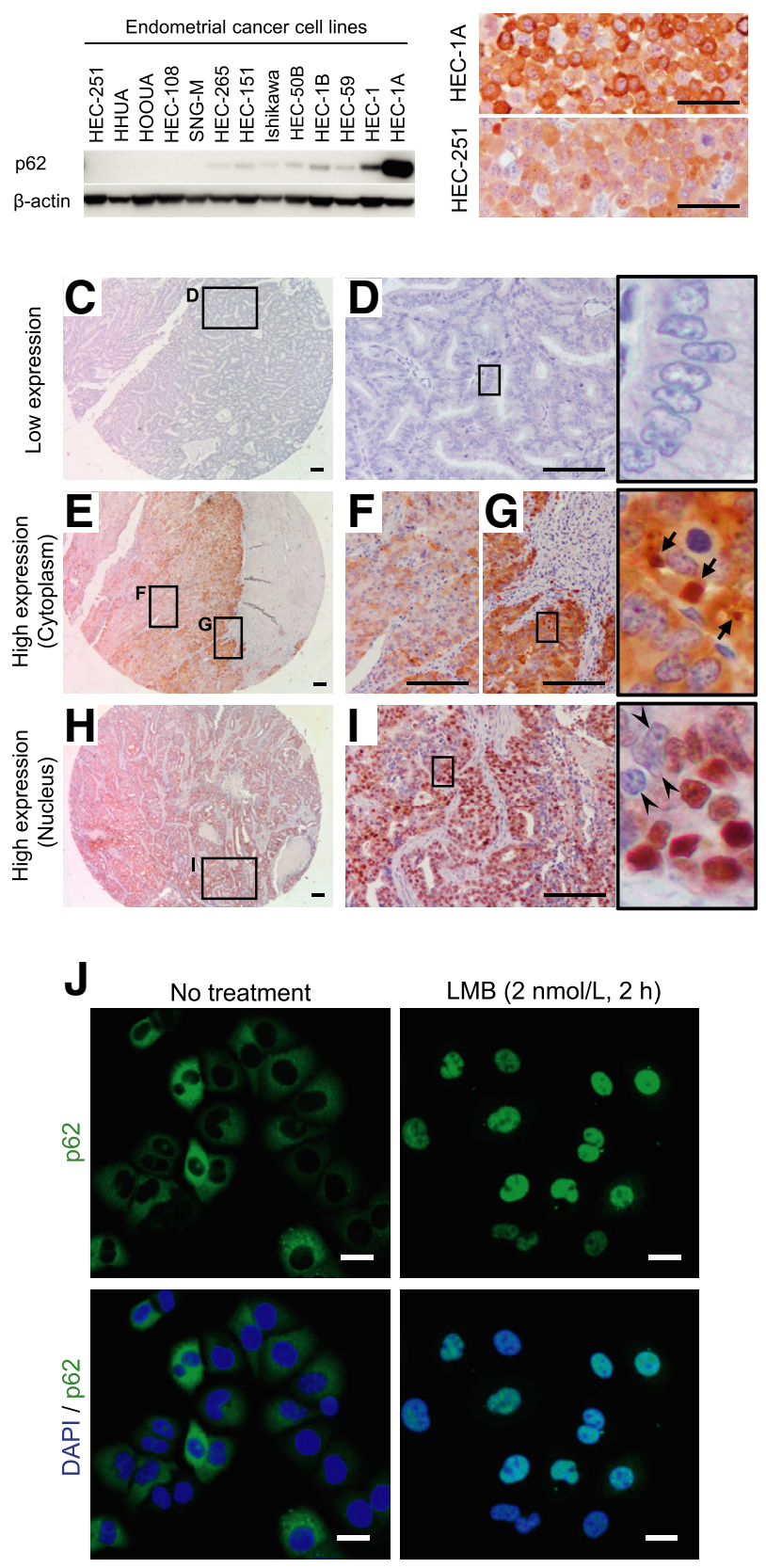

Figure 1 Immunostaining of p62 expression in patients with endometrial cancers. A: Western blot analysis of p62 expression in 13 endometrial cancer cell lines. Whole cell lysate from each cell line was subjected to SDS-PAGE and immunoreacted with the indicated antibodies. B: Representative images of immunostaining of p62 in HEC-1A cells (positive control; top panel) and HEC251 cells (negative control; bottom panel). C and D: Representative images of tumors with low p62 expression. The boxed area in $\mathbf{D}$ is enlarged to the right. E-G: Representative images of tumors with high p62 expression in the cytoplasm. $F$ and $G$ show intratumoral area and invasive front area, respectively. The boxed area in $\mathbf{G}$ is enlarged to the right. Arrows indicate p62-positive aggregate-like structures. $\mathbf{H}$ and I: Representative images of tumors with high p62 expression in the nucleus. The boxed area in I is enlarged to the right. Arrowheads indicate p62-negative nuclei adjacent to p62-positive nuclei. J: Translocation of p62 into the nuclei in leptomycin B (LMB)-treated HEC-1A cells. Cells were treated with $2 \mathrm{nmol} / \mathrm{L}$ of LMB for 2 hours, fixed, and then immunostained with anti-p62 antibody. Nuclei were counterstained with DAPI. Scale bars: $20 \mu \mathrm{m}$ (B and J); $100 \mu \mathrm{m}$ (C-I). cells and lowest in HEC-251 cells by Western blot analysis (Figure 1A). Paraffin blocks of these cells were then prepared, and under optimized conditions, strong p62 signals were observed in the cytoplasm of HEC-1A cells, but not in HEC-251 cells (Figure 1B).

To assess the clinical significance of p62 expression in ECs, we performed immunohistochemical analysis using TMAs from 194 patients with primary ECs. Expression of p62 protein was detected in the cytoplasm and/or nucleus of the EC tumor cells (Figure 1, C-I). High expression of cytoplasmic p62 was observed in $38(19.6 \%)$ of 194 cases and was significantly associated with nonendometrioid types $\left(P=1.53 \times 10^{-2}\right)$ and advanced tumor phenotypes, including high tumor grade $\left(P=1.69 \times 10^{-5}\right)$, deep myometrial invasion $\left(P=2.08 \times 10^{-2}\right)$, vascular invasion $\left(P=5.07 \times 10^{-4}\right)$, and lymph node metastasis $\left(P=3.91 \times 10^{-2}\right)$ (Figure $1, \mathrm{E}-\mathrm{G}$, and Table 1). Patients who had tumors with high expression of cytoplasmic p62 showed significantly shorter overall survival time than those who had tumors with low cytoplasmic p62 expression $\left(P=9.03 \times 10^{-5}\right)$ (Figure 2A). Interestingly, the staining intensity of cytoplasmic p62 seemed to be stronger in the invasive front area than in the intratumoral area within the tumor tissue (Figure 1, E-G). In addition, EC tumor cells with p62-positive aggregate-like structures were occasionally observed in this invasive front area.

p62 Protein shuttles between the nuclear and cytosolic compartments at high rates. ${ }^{33}$ Indeed, we observed that p62 localized in the nucleus in HEC-1A cells treated with leptomycin $\mathrm{B}$, an inhibitor of nuclear export (Figure $1 \mathrm{~J}$ ). Furthermore, immunohistochemical studies of other human cancers have also detected the presence of p62 not only in the cytoplasm, but also in the nucleus. ${ }^{15,20,22,23}$ In our immunohistochemical analysis, immunostaining of p62 protein in the nucleus was observed in some populations of tumor cells (5\% to 80\%) in 70 of 194 cases (Figure 1, H and I) and significantly correlated with prognosis $\left(P=1.50 \times 10^{-2}\right)$ (Figure 2B). On the basis of the expression level (high or low) and distribution (Cyto or $\mathrm{Nuc}$ ), we classified tumors into four subtypes: type A $\left(\right.$ Cyto $\left.^{\text {Low }} / \mathrm{Nuc}^{\text {Low }}: n=95\right)$, type $\mathrm{B}\left(\right.$ Cyto $^{\text {Low }} / \mathrm{Nuc}^{\mathrm{High}}$ : $n=61)$, type $\mathrm{C}\left(\mathrm{Cyto}^{\mathrm{High}} / \mathrm{Nuc}^{\mathrm{High}}: n=9\right)$, and type $\mathrm{D}$ $\left(\right.$ Cyto $^{\text {High }} /$ Nuc $^{\text {Low }}: n=29$ ). Tumors of type $\mathrm{D}$ showed a higher frequency of nonendometrioid types $\left(P=2.31 \times 10^{-3}\right)$, high tumor grade $\left(P=4.41 \times 10^{-6}\right)$, deep myometrial invasion $\left(P=2.51 \times 10^{-2}\right)$, and positive vascular invasion $\left(P=1.25 \times 10^{-2}\right)$ compared with types $\mathrm{A}, \mathrm{B}$, and $\mathrm{C}$ tumors (Table 1). Kaplan-Meier survival curves indicated that patients with type D tumors had a poorer prognosis than those with the other tumor types, not only among the 194 patients with EC $\left(P=5.32 \times 10^{-5}\right)$, but also among the 175 patients with endometrioid adenocarcinoma, 35 patients with grade 3 tumors, and 39 patients with stage III or IV tumors $\left(P=5.51 \times 10^{-3}, 2.73 \times 10^{-3}\right.$, or $3.68 \times 10^{-4}$, respectively) (Figure $2, \mathrm{C}-\mathrm{F}$ ).

Univariate analysis showed that histological type, tumor grade, depth of myometrial invasion, vascular invasion, lymph 

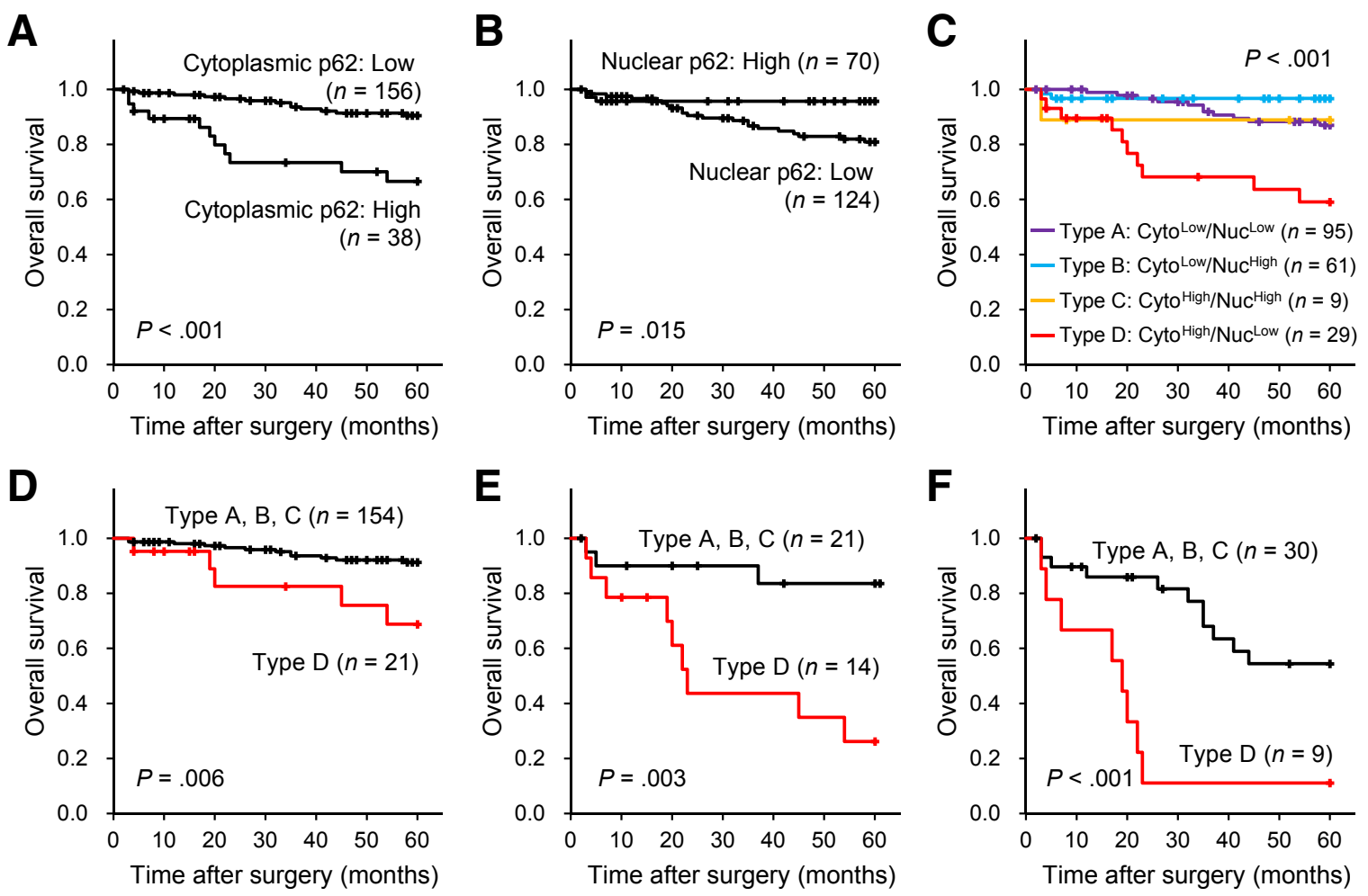

Figure 2 Prognostic implication of p62 expression status in patients with endometrial cancers. A: Overall survival curves of 194 patients with endometrial cancers according to cytoplasmic p62 expression. Survival curves of the 156 patients with tumors that had low expression of cytoplasmic p62 and the 38 patients with tumors that had high expression of cytoplasmic p62 are shown. The two curves differ significantly. B: Overall survival curves of 194 patients with endometrial cancers according to nuclear p62 expression. Survival curves of the 124 patients with tumors that had low expression of nuclear p62 and the 70 patients with tumors that had high expression of nuclear p62. The two curves differ significantly. C: Overall survival curves of the 194 patients with endometrial cancers according to the p62 expression subtypes. This figure shows four survival curves for the patients with type A [cytoplasm (Cyto) ${ }^{\text {Low }} /$ nucleus (Nuc) $^{\text {Low }}$ ], type B (Cyto ${ }^{\text {Low }} /$ Nuc $^{\text {High }}$ ), type C (Cyto ${ }^{\text {High }} /$ Nuc $^{\text {High }}$ ), or type $\mathrm{D}$ (Cyto ${ }^{\text {High }} / \mathrm{Nuc}^{\text {Low }}$ ) tumors. Patients with type $\mathrm{D}$ tumors have significantly shorter overall survival time than the others. D: 0verall survival curves of the 175 patients with endometrioid adenocarcinomas according to the p62 expression subtypes. E: Overall survival curves of the 35 patients with grade 3 tumors according to the p62 expression subtypes. F: Overall survival curves of the 39 patients with stage III and IV tumors according to the p62 expression subtypes. In D-F, patients with type $D$ tumors have significantly shorter overall survival time than patients with other subtypes.

node metastasis, International Federation of Gynecology and Obstetrics stage, residual tumor, and the classification on p62 expression significantly correlated with overall survival. When multivariate analysis was performed using these eight factors, classification of p62 expression was selected as an independent prognostic factor $\left(P=1.06 \times 10^{-2}\right)$, as well as presence of residual tumor $\left(P=1.83 \times 10^{-2}\right)$ (Table 2). Furthermore, in the 175 patients with endometrioid adenocarcinoma, multivariate analysis after univariate analysis revealed that the classification of p62 expression was only an independent prognostic factor for overall survival $\left(P=7.97 \times 10^{-3}\right.$, data not shown). These findings from immunohistochemical analysis suggest that high expression of p62 protein in the cytoplasm may be a molecular marker for poor prognosis of patients with ECs, and may functionally contribute to the acquirement of aggressive phenotype in EC tumor cells.

Effect of p62 Inhibition on Migration, Invasion, and Sensitivity to 0xidative Stress in HEC-1A Cells

Because our immunohistochemical analysis revealed that high expression of cytoplasmic p62 protein correlated with myometrial and vascular invasion, we next examined the effect of p62 inhibition on the in vitro migration and invasion ability of HEC-1A cells, an EC cell line that was observed to have the highest expression of endogenous p62 protein among the examined EC cell lines (Figure 1A). The intracellular distribution of $\mathrm{p} 62$ protein was confined to the cytoplasm (Figure 1, B and J). For p62 inhibition, we used two differential methods: stable inhibition by lentiviralmediated introduction of shRNA targeting p62, and transient inhibition by transfection of siRNA targeting p62. The p62 expression was effectively reduced in both the stably and transiently p62-inhibited cells, when compared with their respective controls (Figure 3A). There was no significant change in cell growth rates under either condition of p62 inhibition (Figure 3B). Migration and invasion assays showed that p62 inhibition significantly reduced invasion ability, but not migration ability $\left(P=1.50 \times 10^{-2}\right.$ for shRNA-introduced cells and $P=1.48 \times 10^{-2}$ for siRNA-transfected cells) (Figure 3, C and D). Reduction of invasion ability by p62 inhibition was also shown in other EC cells, HEC-1 cells $\left(P=5.76 \times 10^{-4}\right)($ Supplemental Figure S1, A-C). In addition, we showed that overexpression of p62 enhanced 
Table 2 Cox Proportional Hazard Regression Analysis for Overall Survival in 194 Patients with Endometrial Cancers

\begin{tabular}{|c|c|c|c|c|c|}
\hline \multirow[b]{2}{*}{ Variables } & \multirow[b]{2}{*}{ Total No. } & \multicolumn{2}{|l|}{ Univariate analyses } & \multicolumn{2}{|l|}{ Multivariate analyses } \\
\hline & & $\mathrm{HR}(95 \% \mathrm{CI})$ & $P$ & $\mathrm{HR}(95 \% \mathrm{CI})$ & $P$ \\
\hline \multicolumn{6}{|l|}{ Age, years } \\
\hline$>60$ & 74 & $2.19(0.98-4.89)$ & & & \\
\hline \multicolumn{6}{|l|}{ Histological type } \\
\hline Endometrioid & 175 & 1.00 & $<0.001$ & 1.00 & 0.741 \\
\hline 1,2 & 159 & 1.00 & $<0.001$ & 1.00 & 0.992 \\
\hline 3 & 35 & $6.12(2.74-13.65)$ & & $0.99(0.36-2.75)$ & \\
\hline \multicolumn{6}{|c|}{ Myometrial invasion, $\%$} \\
\hline$\leq 50$ & 104 & 1.00 & 0.008 & 1.00 & 0.917 \\
\hline$>50$ & 90 & $93.74(3.27-2688.83)$ & & $22,479.49\left(0.00-4.9 \times 10^{86}\right)$ & \\
\hline Negative & 164 & 1.00 & $<0.001$ & 1.00 & 0.810 \\
\hline Positive & 30 & $17.64(7.46-41.67)$ & & $1.18(0.31-4.42)$ & \\
\hline \multicolumn{6}{|l|}{ FIG0 stage } \\
\hline I-II & 155 & 1.00 & $<0.001$ & 1.00 & 0.278 \\
\hline III-IV & 39 & $23.70(8.78-63.94)$ & & $2.65(0.46-15.37)$ & \\
\hline \multicolumn{6}{|l|}{ Residual tumor } \\
\hline Negative & 171 & 1.00 & $<0.001$ & 1.00 & 0.018 \\
\hline Positive & 23 & $25.19(10.6-59.87)$ & & $4.73(1.30-17.21)$ & \\
\hline \multicolumn{6}{|c|}{ Subtypes of p62 expression* } \\
\hline Types A, B, and C & 165 & 1.00 & $<0.001$ & 1.00 & 0.011 \\
\hline Type D & 29 & $5.35(2.37-12.08)$ & & $4.71(1.44-15.44)$ & \\
\hline
\end{tabular}

Statistically significant values are boldfaced.

*Expression status of p62 was determined by immunohistochemistry and was classified as described in Materials and Methods.

FIGO, International Federation of Gynecology and Obstetrics; HR, hazard ratio.

tumor cell invasion in p62-lowly expressing HEC-251 cells $\left(P=6.85 \times 10^{-4}\right)($ Supplemental Figure S1, D-F). These results strongly suggest that high expression of p62 contributes to tumor cell invasion.

It is known that p62 expression contributes to the tolerance of oxidative stress in several cancer cells. ${ }^{5,13,34} \mathrm{We}$, therefore, examined the effect of p62 inhibition on the resistance to oxidative stress in HEC-1A cells. Cell sensitivity to hydrogen peroxide, an oxidative stress inducer, significantly increased in stably p62-inhibited cells $\left(P=8.41 \times 10^{-4}\right)$ and in transiently p62-inhibited cells $\left(P=4.21 \times 10^{-3}\right)$ at $100 \mu \mathrm{mol} / \mathrm{L} \mathrm{H}_{2} \mathrm{O}_{2}$, compared with their respective controls (Figure $3 \mathrm{E}$ ). These results suggest that high expression of cytoplasmic p62 contributes to the invasive ability and tolerance to oxidative stress in EC cells.

\section{Effect of p62 Inhibition on Orthotopic Tumor Development in Vivo}

Because the growth rate of HEC-1A cells was not remarkably affected by shRNA-mediated inhibition of p62 (Figure 3B), we examined the effect of p62 inhibition on orthotopic tumor development by $\mathrm{EC}$ cells in vivo. It is known that the orthotopic injection of HEC-1A cells into the uterus of mice frequently results in tumor development. ${ }^{32}$ By using this system, we injected stably p62-inhibited cells or vector control cells derived from HEC-1A cells into the uterus (Figure 4A). Eight weeks after injection, the entire uterus was excised and tissues other than the tumor mass that had formed around the injection site were trimmed away (Figure 4B). The weight of the tumor mass derived from stably p62-inhibited cells was reduced compared with tumors derived from the vector control cells $\left(P=2.65 \times 10^{-2}, n=5\right.$ for both cell types) (Figure 4C). Immunohistochemical analysis on sections from the excised tumor revealed that the staining intensity of $\mathrm{p} 62$ protein was stronger in the invasive front area compared with the intratumoral area in tumors derived from vector control cells, consistent with the observations from primary EC tumors (Figure 1, E-G, and Figure 4, D-G), whereas this distribution of p62 was less pronounced within tumors derived from stably p62-inhibited cells (Figure 4, H-K). The incident of lymph node metastasis was assessed at 12 weeks after injection of control vector cells $(n=3)$ or stably p62-inhibited cells $(n=4)$. Metastatic nodules were observed in two para-aortic lymph nodes in one of the two 
mice bearing primary tumors from control vector cells (Figure 4, L-O), whereas there was no lymph node metastasis in two mice bearing primary tumors from stably p62-inhibited cells. Taken together, these findings suggest that high expression of p62 in the cytoplasm in EC tumor cells functionally contributes to the acquirement of aggressive phenotype, including tumor growth and invasion.

A

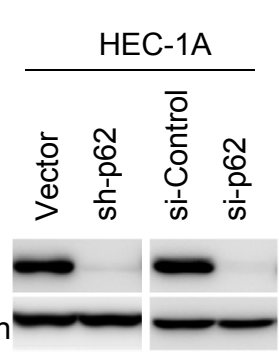

C

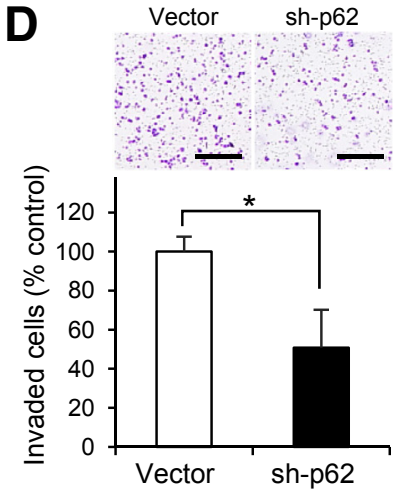

E

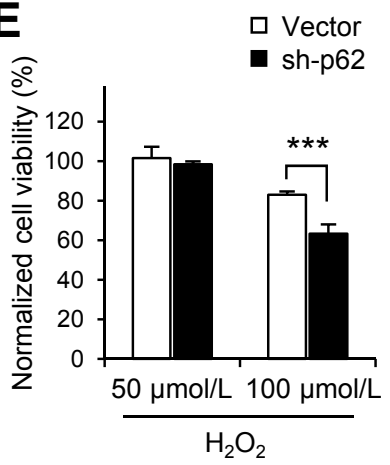

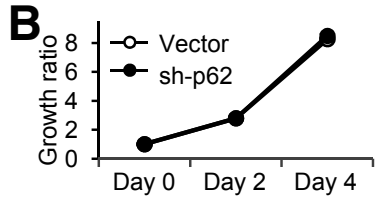
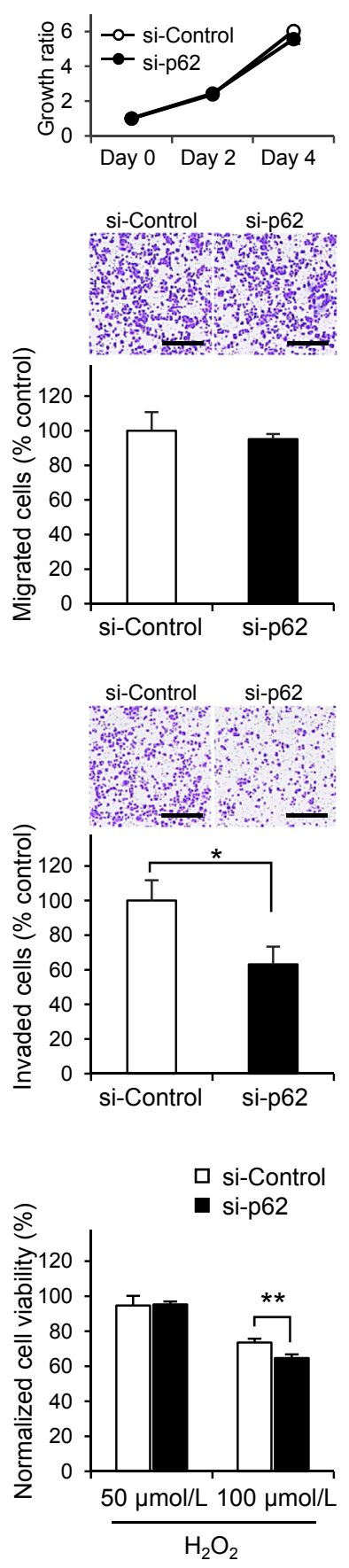

\section{Discussion}

In the present cohort, we observed that the type D $\left(\mathrm{Cyto}^{\mathrm{High}}\right.$ / Nuc $^{\text {Low }}$ ) subtype for p62 expression status significantly correlated with histological grade and tumor invasion, and may be used as a powerful prognostic factor. Although high expression of cytoplasmic p62 also correlates with nonendometrioid histology, it is caused by frequently arising high-grade tumor and deep myometrial invasion in nonendometrioid cancer compared with endometrioid cancer. Patients with EC tumors that had high expression of cytoplasmic p62 had a significantly shorter overall survival time than those with tumors that had low expression of cytoplasmic p62; multivariate analysis for overall survival showed that p62 positivity is an independent prognostic indicator in patients with EC. To our knowledge, this is the first report to show the clinical implication of p62 expression in ECs.

In the present study, we showed that a high expression level of p62 protein could be observed in some EC tumors; however, the mechanism underlying this observation remains unclear. Although p62 protein is constantly degraded by the autophagy system, it has been demonstrated that it accumulates in liver tumors that develop in mice lacking the $\operatorname{Atg} 5$ or Atg7 genes. ${ }^{5,9,10}$ On the other hand, it is known that p62 expression is regulated in a cellular-condition-dependent manner at the transcriptional level. ${ }^{34-36}$ It has been shown that the p62 mRNA level positively correlates with its protein level, as examined by immunohistochemistry in oral squamous cell carcinomas, ${ }^{22}$ suggesting that a high expression of p62 protein may be attributed to dysregulation at the transcription and/or translation level.

In our immunohistochemical analysis, we observed two characteristic distributions of p62. One of these is the immunoreactivity of p62 in the nucleus (Figure 1, H and I),

Figure 3 Effect of p62 inhibition on migration, invasion, and sensitivity to oxidative stress in HEC-1A cells. A: Western blot analysis of p62 expression in stably p62-inhibited cells (sh-p62) and vector control cells (Vector Laboratories), as well as transiently p62-inhibited cells (si-p62) and control-siRNA-transfected cells (si-Control). Whole cell lysate was subjected to SDS-PAGE and immunoreacted with the indicated antibodies. B: Cell growth assays in p62-inhibited cells. Growth indicates the growth ratios at day 2 or 4 relative to day 0 . The growth ratios between stably p62inhibited and vector control cells as well as transiently p62-inhibited cells and control-siRNA-transfected cells do not change. C: Migration assay with p62-inhibited cells. D: Invasion assay with p62-inhibited cells. In $\mathbf{C}$ and $\mathbf{D}$, stably or transiently p62-inhibited cells were transferred into the upper chambers in serum-free medium $\left(1 \times 10^{5}\right.$ cells per well). After incubation for 24 hours, cells that migrated or invaded into the lower chambers that contained $10 \%$ fetal bovine serum as the chemoattractant were stained with $0.1 \%$ crystal violet in $4 \%$ formaldehyde in phosphate-buffered saline (PBS). The stained cells were counted using ImageJ software. E: Normalized cell viability after treatment with hydrogen peroxide. Cells were exposed to 0 , 50, or $100 \mu \mathrm{mol} / \mathrm{L} \mathrm{H}_{2} \mathrm{O}_{2}$ for 3 hours, followed by a change to maintenance medium and incubation for an additional 3 days. Viable cells were fixed and stained with $0.1 \%$ crystal violet in $4 \%$ formaldehyde in PBS. Fixed cells were lysed by $2 \%$ SDS, and absorbance was measured at $560 \mathrm{~nm}$. Data are presented as means \pm SD (D). ${ }^{*} P<0.05,{ }^{* *} P<0.01$, and ${ }^{* * *} P<0.001$. Scale bars: $500 \mu \mathrm{m}$ (C and D). 

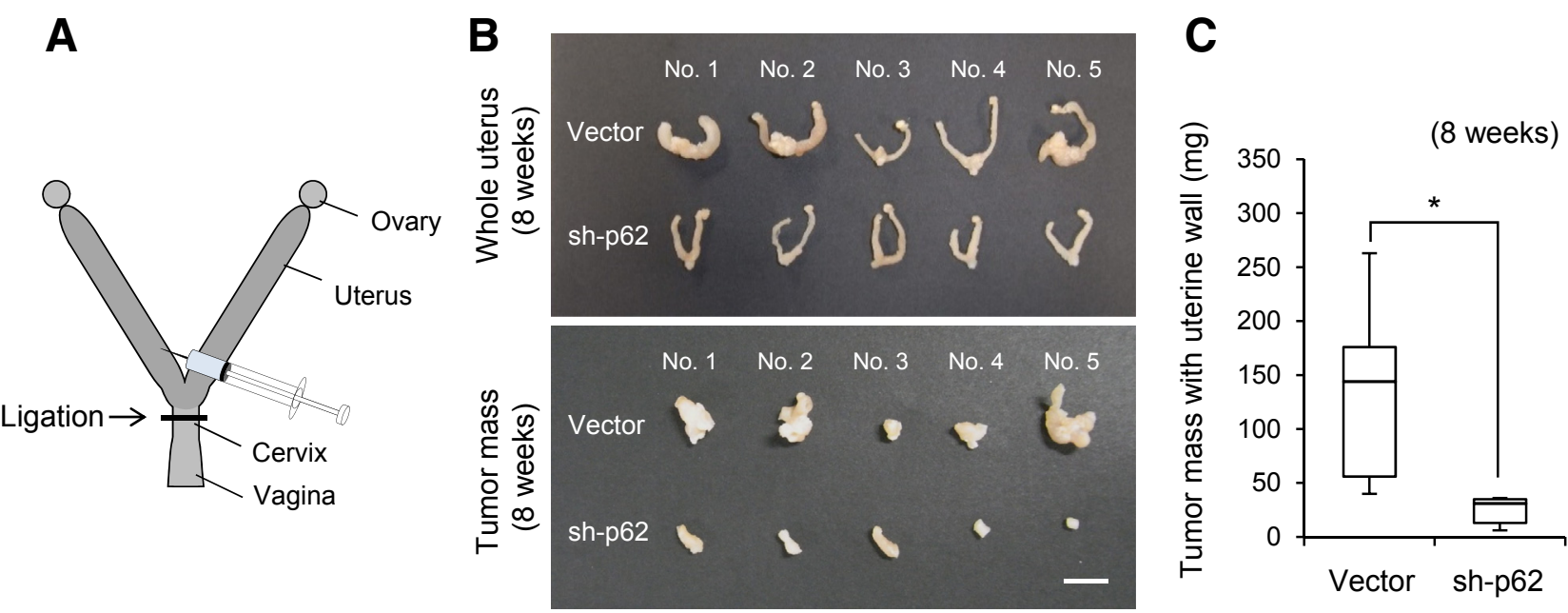

$H \& E$
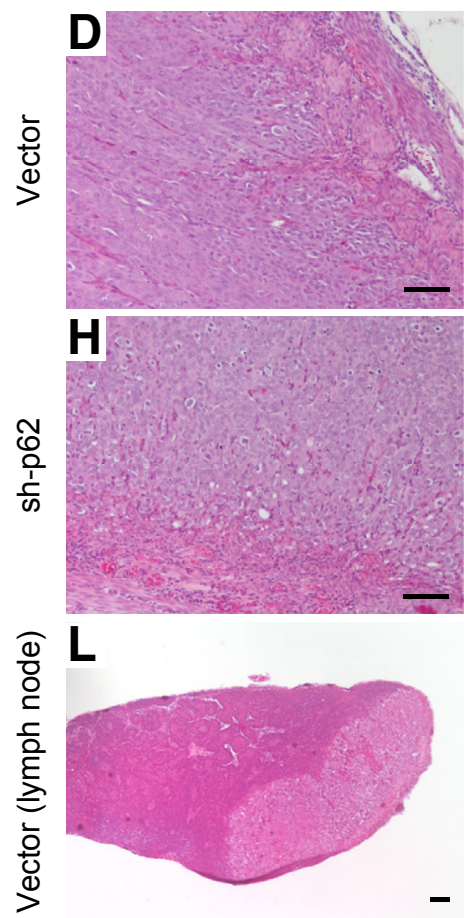

p62
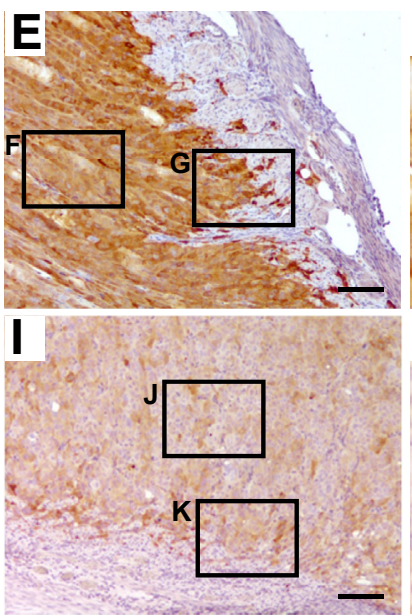

\section{M}

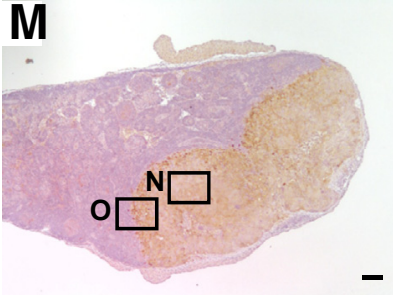

p62, intratumor (enlarged)
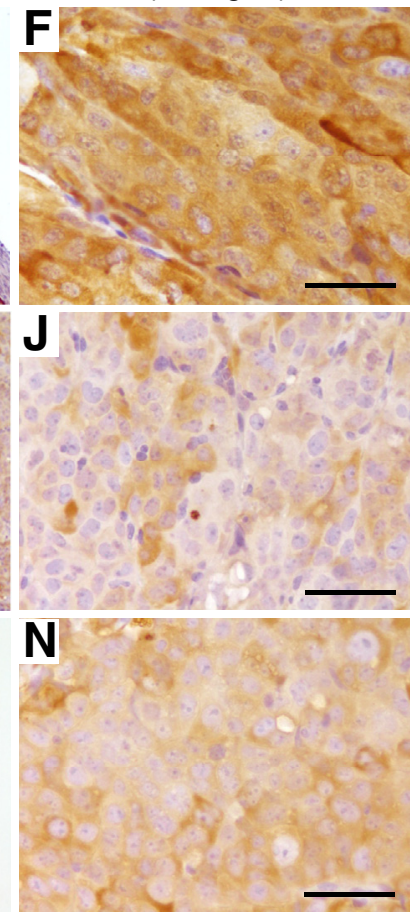

p62, invasive front (enlarged)
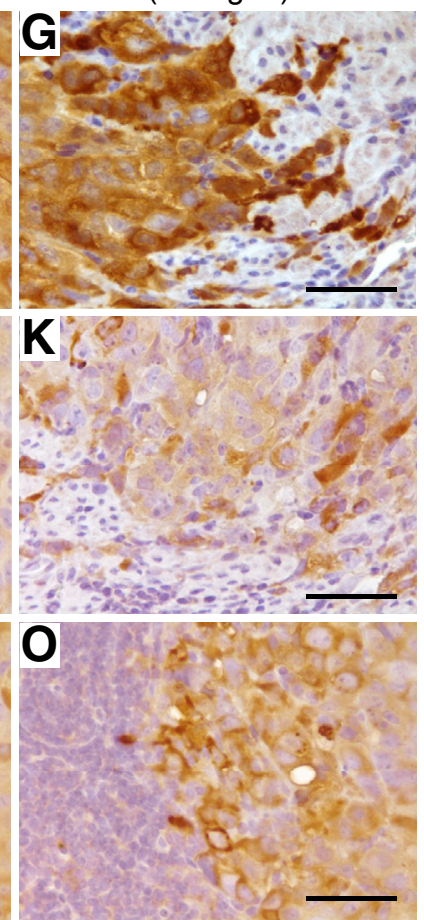

Figure 4 Effect of p62 inhibition on orthotopic tumor development in vivo. A: Orthotopic implantation model. Stably p62-inhibited cells and vector control cells were suspended in $30 \mu \mathrm{L}$ of Matrigel and injected into the right uterus cavity, after ligation by absorbable suture at the boundary division of the uterine fundus and cervix. B: Representative images of the excised uterus and the tumor mass. Mice were sacrificed at 8 weeks after injection, and the entire uterus was excised and tissues other than the tumor mass that had formed around the injection site were trimmed away. C: Weight of the excised tumor mass. Data are indicated in the boxand-whisker plot. D-G: Representative images for hematoxylin and eosin (H\&E) staining (D) or p62 immunostaining (E-G) in sections of the tumors derived from vector control cells at 8 weeks. H-K: Representative images for H\&E staining $(\mathbf{H})$ or p62 immunostaining $(\mathbf{I}-\mathbf{K})$ in sections of the tumors derived from stably p62inhibited cells at 8 weeks. L-0: Representative images for H\&E staining (L) or p62 immunostaining (M-0) in sections of the metastatic tumor in the para-aortic lymph node derived from vector control cells at 12 weeks. ${ }^{\star} P<0.05$. Scale bars: $100 \mu \mathrm{m}(\mathbf{D}, \mathbf{E}, \mathbf{H}, \mathbf{I}, \mathbf{L}$, and $\mathbf{M}) ; 50 \mu \mathrm{m}(\mathbf{F}, \mathbf{G}, \mathbf{J}, \mathbf{K}, \mathbf{N}$, and $\mathbf{0})$.

which has been previously reported in other human cancers, including prostate, breast, oral, and ovarian cancers. ${ }^{15,20,22,23}$ Furthermore, it has been experimentally demonstrated that the p62 protein is shuttled between the nuclear and cytosolic compartments by its signals for nuclear localization and export. ${ }^{33}$ Interestingly, we found that patients with tumors that had positive nuclear staining had a good prognosis compared with patients with tumors that had negative nuclear staining, independent of high p62 expression in the cytoplasm. This suggests that localization of $\mathrm{p} 62$ protein in the nucleus may attenuate the malignancy of EC cells; however, the function of p62 in the nucleus is largely unknown (Figure 2B). It may be 
related to the fact that nuclear p62 can interact with the promyelocytic leukemia bodies, which are involved in the regulation of gene transcription, apoptosis, and DNA damage response, in the nucleus. ${ }^{33}$

Higher expression of p62 in the invasive front area compared with the intratumoral area was also observed as a characteristic distribution in both primary EC tumors with high expression of cytoplasmic p62 and tumors from xenograft mouse models (Figure 1, E-G, and Figure 4, E-G and M-O). In this invasive front area, EC tumor cells with p62-positive aggregate-like structures were occasionally observed. Many studies have suggested that excess p62 expression may contribute to tumor growth and tolerance to cellular stress through the activation of various oncogenic signals. ${ }^{5,10-13}$ High expression of p62 promotes tumor necrosis factor receptor associated factor 6 ubiquitination in the cytoplasm, resulting in activation of NF- $\kappa \mathrm{B}$ to enhance cell survival. ${ }^{5}$ Furthermore, the localization at the lysosomal surface of p62 involves inactivation of the mTOR pathway. ${ }^{12}$ In hepatocellular carcinoma, p62 is highly expressed and frequently distributed as aggregate structures in the cytoplasm. ${ }^{10}$ Although an oncogenic oxidative stress response protein, NRF2, is constantly degraded by Kelch-like ECH-associated protein 1-cullin-3 complex, it has been known that the formation of p62-positive aggregate structure contributes to constitutive stabilization of NRF2 via trapping of KEAP1 and competitive inhibition of NRF2-KEAP1 interaction. ${ }^{5,10,14}$ These evidences suggest that high expression level of cytoplasmic p62 may contribute to tumorigenesis and tumor malignancy. In addition, our findings above experimentally demonstrate that cytoplasmic p62 expression may be involved not only in tumor growth and tolerance to cellular stress, but also in tumor invasion and lymph node metastasis. Even though there was no influence of p62 inhibition on in vitro cell growth, p62 inhibition resulted in the significant reduction of in vivo tumor mass, suggesting that p62 may contribute to survival of EC cells under the stress condition, such as hypoxia and low nutrient within tumor microenvironment. Also, the interaction between EC cells and adjacent stromal cells in the invasive front area may be a candidate for the trigger of high cytoplasmic expression of p62 and/or the formation of p62-positive aggregate-like structures.

In summary, we identified that the type $\mathrm{D}$ (Cyto ${ }^{\mathrm{High}} / \mathrm{Nuc}{ }^{\mathrm{Low}}$ ) p62 expression subtype may be used as a new prognostic marker on the basis of the biological evidence at the molecular level in ECs. In addition, the subcellular distribution of p62 is heterogeneous, and is characterized by localization in the cytoplasm or nucleus and strong expression of cytoplasmic p62 at the invasive front area. Therefore, further studies are warranted for understanding the significance of this heterogeneous distribution of p62 to develop a personalized therapeutic approach for cancers, including ECs, with a high expression of cytoplasmic p62.

\section{Acknowledgments}

We thank Ayako Takahashi and Rumi Mori for technical assistance and Drs. Hiroyuki Kuramoto (Kanagawa Health
Service Association, Kanagawa, Japan), Isamu Ishiwata (Ishiwata Obstetrics and Gynecology Hospital, Ibaraki-ken, Japan), and Masato Nishida (Kasumigaura Medical Center, Tsuchiura, Japan) for HEC-1A, HEC-1B, and HEC-108; HHUA and HOOUA; and Ishikawa cells, respectively.

R.I., J. Inoue, and J. Inazawa conceived the experiments. R.I., J. Inoue, and H.T. developed the methods. R.I., J. Inoue, H.T., M.T., and K.F. acquired and interpreted the data. R.I., J. Inoue, and J. Inazawa analyzed and interpreted the data. R.I., J. Inoue, and J. Inazawa wrote, reviewed, and revised the manuscript. H.T., A.H., and D.A. provided administrative, technical, and material support. D.A. and J. Inazawa supervised the study.

\section{Supplemental Data}

Supplemental material for this article can be found at http://dx.doi.org/10.1016/j.ajpath.2015.05.008.

\section{References}

1. Ferlay J, Soerjomataram I, Ervik M, Dikshit R, Eser S, Mathers C, Rebelo M, Parkin DM, Forman D, Bray F: GLOBOCAN 2012 v1.0, Cancer Incidence and Mortality Worldwide: IARC CancerBase No. 11 [Internet]. Lyon, France, International Agency for Research on Cancer, [cited August 22, 2014]. Available at, http://globocan.iarc.fr

2. Sorosky JI: Endometrial cancer. Obstet Gynecol 2012, 120:383-397

3. Colombo N, Preti E, Landoni F, Carinelli S, Colombo A, Marini C, Sessa C; ESMO Guidelines Working Group: Endometrial cancer: ESMO Clinical Practice Guidelines for diagnosis, treatment and follow-up. Ann Oncol 2013, 24(Suppl 6):vi33-vi38

4. Katanoda K, Matsuda T, Matsuda A, Shibata A, Nishino Y, Fujita M, Soda M, Ioka A, Sobue T, Nishimoto H: An updated report of the trends in cancer incidence and mortality in Japan. Jpn J Clin Oncol 2013, 43:492-507

5. Komatsu M, Kageyama S, Ichimura Y: p62/SQSTM1/A170: physiology and pathology. Pharmacol Res 2012, 66:547-562

6. Bjørkøy G, Lamark T, Brech A, Outzen H, Perander M, Overvatn A, Stenmark H, Johansen T: p62/SQSTM1 forms protein aggregates degraded by autophagy and has a protective effect on huntingtininduced cell death. J Cell Biol 2005, 171:603-614

7. Pankiv S, Clausen TH, Lamark T, Brech A, Bruun JA, Outzen $H$ Øvervatn A, Bjørkøy G, Johansen T: p62/SQSTM1 binds directly to Atg8/LC3 to facilitate degradation of ubiquitinated protein aggregates by autophagy. J Biol Chem 2007, 282:24131-24145

8. Ichimura Y, Kumanomidou T, Sou YS, Mizushima T, Ezaki J, Ueno T, Kominami E, Yamane T, Tanaka K, Komatsu M: Structural basis for sorting mechanism of p62 in selective autophagy. J Biol Chem 2008, 283:22847-22857

9. Takamura A, Komatsu M, Hara T, Sakamoto A, Kishi C, Waguri S, Eishi Y, Hino O, Tanaka K, Mizushima N: Autophagy-deficient mice develop multiple liver tumors. Genes Dev 2011, 25:795-800

10. Inami $\mathrm{Y}$, Waguri $\mathrm{S}$, Sakamoto $\mathrm{A}$, Kouno $\mathrm{T}$, Nakada $\mathrm{K}$, Hino $\mathrm{O}$, Watanabe S, Ando J, Iwadate M, Yamamoto M, Lee MS, Tanaka K, Komatsu M: Persistent activation of Nrf2 through p62 in hepatocellular carcinoma cells. J Cell Biol 2011, 193:275-284

11. Cai-McRae X, Zhong H, Karantza V: Sequestosome 1/p62 facilitates HER2-induced mammary tumorigenesis through multiple signaling pathways. Oncogene 2015, 34:2968-2977

12. Duran A, Amanchy R, Linares JF, Joshi J, Abu-Baker S, Porollo A, Hansen M, Moscat J, Diaz-Meco MT: p62 Is a key regulator of nutrient sensing in the nTORC1 pathway. Mol Cell 2011, 44:134-146 
13. Li L, Shen C, Nakamura E, Ando K, Signoretti S, Beroukhim R, Cowley GS, Lizotte P, Liberzon E, Bair S, Root DE, Tamayo P, Tsherniak A, Cheng SC, Tabak B, Jacobsen A, Hakimi AA, Schultz N, Ciriello G, Sander C, Hsieh JJ, Kaelin WG Jr: SQSTM1 is a pathogenic target of $5 \mathrm{q}$ copy number gains in kidney cancer. Cancer Cell 2013, 24:738-750

14. Lau A, Wang XJ, Zhao F, Villeneuve NF, Wu T, Jiang T, Sun Z, White E, Zhang DD: A noncanonical mechanism of Nrf2 activation by autophagy deficiency: direct interaction between Keap1 and p62. Mol Cell Biol 2010, 30:3275-3285

15. Kitamura H, Torigoe T, Asanuma H, Hisasue SI, Suzuki K, Tsukamoto T, Satoh M, Sato N: Cytosolic overexpression of p62 sequestosome 1 in neoplastic prostate tissue. Histopathology 2006, 48: $157-161$

16. Giatromanolaki A, Sivridis E, Mendrinos S, Koutsopoulos AV, Koukourakis MI: Autophagy proteins in prostate cancer: relation with anaerobic metabolism and Gleason score. Urol Oncol 2014, 32: e11-e18

17. Inoue D, Suzuki T, Mitsuishi Y, Miki Y, Suzuki S, Sugawara S, Watanabe M, Sakurada A, Endo C, Uruno A, Sasano H, Nakagawa T, Satoh K, Tanaka N, Kubo H, Motohashi H, Yamamoto M: Accumulation of p62/SQSTM1 is associated with poor prognosis in patients with lung adenocarcinoma. Cancer Sci 2012, 103:760-766

18. Rolland P, Madjd Z, Durrant L, Ellis IO, Layfield R, Spendlove I: The ubiquitin-binding protein p62 is expressed in breast cancers showing features of aggressive disease. Endocr Relat Cancer 2007, 14:73-80

19. Luo RZ, Yuan ZY, Li M, Xi SY, Fu J, He J: Accumulation of p62 is associated with poor prognosis in patients with triple-negative breast cancer. Onco Targets Ther 2013, 6:883-888

20. Choi J, Kim do H, Jung WH, Koo JS: Metabolic interaction between cancer cells and stromal cells according to breast cancer molecular subtype. Breast Cancer Res 2013, 15:R78

21. Inui T, Chano T, Takikita-Suzuki M, Nishikawa M, Yamamoto G, Okabe H: Association of p62/SQSTM1 excess and oral carcinogenesis. PLoS One 2013, 8:e74398

22. Liu JL, Chen FF, Lung J, Lo CH, Lee FH, Lu YC, Hung CH: Prognostic significance of p62/SQSTM1 subcellular localization and LC3B in oral squamous cell carcinoma. Br J Cancer 2014, 111:944-954

23. Iwadate R, Inoue J, Tsuda H, Takano M, Furuya K, Hirasawa A, Aoki D, Inazawa J: High expression of SQSTM1/p62 protein is associated with poor prognosis in epithelial ovarian cancer. Acta Histochem Cytochem 2014, 47:295-301

24. Kuramoto H, Hamano M, Imai M, Fujisawa T, Kamata Y, Arai T, Kawaguchi M: HEC-1 cells: establishment of an in vitro experimental system in endometrial carcinoma. Edited by Kuramoto H, Nishida M.
Cell and Molecular Biology of Endometrial Carcinoma. Tokyo, Springer-Verlag Tokyo, 2003, pp 3-34

25. Morisawa T: The results of primary culture of endometrial adenocarcinoma and characterization of its established cell lines [Japanese]. J Jpn Soc Clin Cytol 1987, 26:433-442

26. Ishiwata I, Ishiwata C, Soma M, Arai J, Ishikawa H: Establishment of human endometrial adenocarcinoma cell line containing estradiol-17 beta and progesterone receptors. Gynecol Oncol 1984, 17:281-290

27. Fujita N, Yaegashi N, Ide Y, Sato S, Nakamura M, Ishiwata I, Yajima A: Expression of CD44 in normal human versus tumor endometrial tissues: possible implication of reduced expression of CD44 in lymph-vascular space involvement of cancer cells. Cancer Res 1994, 54:3922-3928

28. Nishida M: Ishikawa cells: opening of in vitro hormone research on endometrial carcinoma. Edited by Kuramoto H, Nishida M. Cell and Molecular Biology of Endometrial Carcinoma. Tokyo, SpringerVerlag Tokyo, 2003, pp 35-58

29. Ishiwata I, Nozawa S, Inoue T, Okumura H: Development and characterization of established cell lines from primary and metastatic regions of human endometrial adenocarcinoma. Cancer Res 1977, 37:1777-1785

30. Kobayashi T, Masutomi K, Tamura K, Moriya T, Yamasaki T, Fujiwara Y, Takahashi S, Yamamoto J, Tsuda H: Nucleostemin expression in invasive breast cancer. BMC Cancer 2014, 14:215

31. Haruki S, Imoto I, Kozaki K, Matsui T, Kawachi H, Komatsu S, Muramatsu T, Shimada Y, Kawano T, Inazawa J: Frequent silencing of protocadherin 17, a candidate tumour suppressor for esophageal squamous cell carcinoma. Carcinogenesis 2010, 31:1027-1036

32. Takahashi K, Saga Y, Mizukami H, Takei Y, Urabe M, Kume A, Suzuki M, Ozawa K: Development of a mouse model for lymph node metastasis with endometrial cancer. Cancer Sci 2011, 102:2272-2277

33. Lu C, Shao C, Cobos E, Singh KP, Gao W: Chemotherapeutic sensitization of leptomycin B resistant lung cancer cells by pretreatment with doxorubicin. PLoS One 2012, 7:e32895

34. Liu Y, Kern JT, Walker JR, Johnson JA, Schultz PG, Luesch H: A genomic screen for activators of the antioxidant response element. Proc Natl Acad Sci U S A 2007, 104:5205-5210

35. Sahani MH, Itakura E, Mizushima N: Expression of the autophagy substrate SQSTM1/p62 is restored during prolonged starvation depending on transcriptional upregulation and autophagy-derived amino acids. Autophagy 2014, 10:431-441

36. Jain A, Lamark T, Sjøttem E, Larsen KB, Awuh JA, Øvervatn A, McMahon M, Hayes JD, Johansen T: p62/SQSTM1 is a target gene for transcription factor NRF2 and creates a positive feedback loop by inducing antioxidant response element-driven gene transcription. J Biol Chem 2010, 285:22576-22591 